\title{
Lidocaine protects H9c2 cells from hypoxia-induced injury through regulation of the MAPK/ERK/NF-кB signaling pathway
}

\author{
HAIBIN JIN ${ }^{1}$ and JIN YU ${ }^{2}$ \\ ${ }^{1}$ Department of Cardiology, Tianjin Hospital, Tianjin 300211; ${ }^{2}$ Department of Anesthesiology, \\ People's Liberation Army 951 Hospital, Korla, Xinjiang 841000, P.R. China
}

Received February 2, 2019; Accepted August 16, 2019

DOI: $10.3892 /$ etm.2019.8055

\begin{abstract}
The aim of the present study was to investigate the effect of Lidocaine on hypoxia-induced injury in cardiomyoblasts whilst exploring the associated molecular mechanism. In the present study, hypoxia was induced in H9c2 cells to establish an in vitro model of myocardial infarction. The cells were treated with lidocaine $(0.5,1,5,10 \mathrm{mM})$ for $48 \mathrm{~h}$ under hypoxic conditions. Cell viability and apoptosis levels were determined by MTT assay and flow cytometry, and ELISA was used to measure the levels of inflammatory cytokines released. A creatine kinase isoenzyme/cardiac troponin I detection kit was used to show that lidocaine significantly reduced hypoxia-induced cardiac troponin 1 and creatine kinase-muscle/brain release in a dose-dependent manner. Mitochondrial viability staining suggested that lidocaine significantly enhanced mitochondrial viability under hypoxic conditions. Lidocaine also significantly reduced hypoxia-induced apoptosis and increased H9c2 viability in a dose-dependent manner. Additionally, under hypoxic conditions, lidocaine dose-dependently promoted $\mathrm{Bcl}-2$ expression, while decreasing Bax and caspase-3 expression in $\mathrm{H} 9 \mathrm{c} 2$ cells. ELISA and reverse transcription quantitative PCR were used to detect the levels of tumor necrosis factor (TNF- $\alpha$ ), interleukin (IL)-1 $\beta$ and IL- 6 released by H9c2 cells. Results showed that lidocaine markedly reduced the hypoxia-induced expression levels of IL- $1 \beta$, TNF- $\alpha$ and IL-6 in a dose-dependent manner. In addition, protein levels of phosphorylated (p)-ERK1/2 and NF- $\mathrm{BB}$ p-p65 were analyzed by western blotting, and results indicated that lidocaine significantly increased the protein levels of p-ERK1/2 and decreased the protein level of NF- $\kappa B$ p-p65 in a dose-dependent manner under hypoxic conditions. These data
\end{abstract}

Correspondence to: Dr Jin Yu, Department of Anesthesiology, People's Liberation Army 951 Hospital, 7 Tiemenguan Road, Korla, Xinjiang 841000, P.R. China

E-mail: yujin190225@163.com

Key words: myocardial infarction, cardiomyocyte, lidocaine, mitogen activated protein kinase/ERK/NF- $\kappa \mathrm{B}$ signaling pathway, hypoxia suggested that lidocaine might protect cardiomyoblasts from hypoxia-induced injury via activation of the mitogen activated protein kinase/ERK/NF- $\kappa \mathrm{B}$ signaling pathway.

\section{Introduction}

Myocardial infarction (MI) has a high rate of mortality and morbidity worldwide and due to the growth of an aging population the healthcare burden of MI is increasing (1). MI is characterized by inflammation and cardiomyocyte apoptosis, and can lead to left ventricular enlargement, thoracalgia, breathing difficulty, asthenia, fatigue, diaphoresis, cardiopalmus, heart failure and coma $(2,3)$. Coronary artery occlusion is one of the main causes of MI. With the discovery of an increasing number of therapeutic approaches, long-term survival after MI is increasing worldwide (4). Experimental and clinical studies have shown that cardiomyocyte apoptosis following MI is caused by hypoxic injury, ischemia-reperfusion injury and oxidative stress. Mitigation of these processes is a feasible way to treat MI (5).

Cardiomyocyte dysfunction is regarded as a leading cause of cardiac abnormality and may be responsible for the high mortality of patients with heart failure (6). Evidence has shown that myocardial ischaemia-induced cardiomyocyte dysfunction may be a contributor to cardiac cell death (7). MI is the main cause of death in patients with cardiovascular disease (8). Myocardial damage in hypoxia leads to various chemical and physical changes, including scarring, inflammation, necrosis, cell apoptosis and cardiac remodeling (9). An increasing number of studies have highlighted the significance of cardiomyocyte apoptosis and inflammatory response in MI development, due to their role in regulating heart and cardiac muscle function $(9,10)$. A previous study has shown that increased levels of inflammatory mediators in cardiac dysfunction, especially increased levels of tumor necrosis factor- $\alpha$ (TNF- $\alpha$ ) in the locally infarcted myocardium, directly lead to cardiomyocyte apoptosis and myocardial dysfunction (11). Though signaling pathways, including inflammatory and calcium signaling, and reactive oxygen species (ROS) have been shown to play important roles in hypoxia-induced cardiomyocyte apoptosis, the precise molecular mechanisms underlying MI-induced cardiac damage remain unclear (12).

Lidocaine, also known as N-diethylaminoacetyl-2, 6-dimethylaniline, is one of the most commonly used local 
anesthetics (13) and an anti-arrhythmic drug in a number of heart conditions $(14,15)$. Lidocaine has a variety of pharmacological effects, including immunomodulation, anti-inflammatory, anti-oxidative effects and anti-tumor effects (16-21). One study assessing lidocaine toxicity showed that it can inhibit major cell signaling pathways, including AKT and ERK (22). Studies have indicated that lidocaine has a protective effect against cardiomyocyte injury $(23,24)$. Lidocaine-induced blockade of voltage-gated sodium channels has been shown to rescue the function of ischemic myocardium in vivo (23) and has been confirmed to protect mice from myocardial damage due to ischemia-reperfusion injury (24). In particular, Okamoto et al (25) previously reported that hypoxia inducible factor $1 \alpha$ overexpression reduces lidocaine-induced renal cell-derived RCC4 cell and neuronal SH-SY5Y cell death. However, lidocaine has not been previously investigated as a potential treatment for hypoxia-induced cardiomyocyte cell death, and the protective mechanisms of lidocaine in this process remain unclear. Based on existing research data (23-25), it was hypothesized that lidocaine may have a protective effect against hypoxia-induced apoptosis and cardiac damage through the activation of the mitogen activated protein kinase (MAPK) $/ \mathrm{ERK} / \mathrm{NF}-\kappa \mathrm{B}$ signaling pathway. The purpose of this study was to explore this hypothesis and the underlying mechanisms of lidocaine action to provide the basis for developing new treatments for MI.

\section{Materials and methods}

Cell culture and hypoxia treatment. The rat cardiac myoblast cell line H9c2 was obtained from the American Type Culture Collection and they are used here as model for cardiac myocytes. H9c2 cells were cultured in DMEM (Gibco; Thermo Fisher Scientific, Inc.) supplemented with $10 \%$ fetal bovine serum (Invitrogen; Thermo Fisher Scientific, Inc.), $100 \mathrm{U} / \mathrm{ml}$ penicillin and $100 \mathrm{mg} / \mathrm{ml}$ of streptomycin (Sigma-Aldrich; Merck KGaA). Cells were cultured at $37^{\circ} \mathrm{C}$ in a humidified atmosphere of $5 \%$ $\mathrm{CO}_{2}$. Culture medium was changed every 2 days.

To induce hypoxia, $\mathrm{H} 9 \mathrm{c} 2$ cells $\left(5 \times 10^{4} /\right.$ well) at $80 \%$ confluence were placed in a hypoxic chamber (Thermo Fisher Scientific, Inc.) containing $1 \% \mathrm{O}_{2}, 5 \% \mathrm{CO}_{2}$ and $94 \%$ $\mathrm{N}_{2}$ for $48 \mathrm{~h}$. Cells were cultured with a range of lidocaine (Sigma-Aldrich, Merck KGaA; dissolved in sterile water) concentrations $(0.5,1,5,10 \mathrm{mM})$ for $48 \mathrm{~h}$ from the onset of hypoxia. The concentrations of lidocaine used were based on a previous study (26). Cells in the control group were incubated at $37^{\circ} \mathrm{C}$ in a humidified atmosphere of $5 \% \mathrm{CO}_{2}$.

Cellular injury assessment. H9c2 cells were treated with lidocaine $(0.5,1,5,10 \mathrm{mM})$ for $48 \mathrm{~h}$ under hypoxic conditions before a rat cardiac troponin (cTnI) ELISA kit (cat. no. CSB-E08594r; Cusabio Technology LLC) and a rat creatine kinase-muscle/brain (CK-MB) ELISA kit (cat. no. CSB-E14403r; Cusabio Technology LLC) were used to evaluate cTnI and CK-MB release into the cell culture medium. Data were presented as the fold change of the control group (6). During these experiments, the activity of mitochondria in the different treatment groups was measured using Mitochondrial Viability Stain (cat. no. ab129732; Abcam) according to manufacturer's protocol (6).
Cell viability assay. Cell viability was determined using the MTT assay (Beyotime Institute of Biotechnology). H9c2 cells were cultured in 96-well plates, and $\sim 5,000$ cells per well adhered to the culture dish wall. After incubation of cells with $0.5,1,5$ and $10 \mathrm{mM}$ lidocaine for $48 \mathrm{~h}$ under hypoxic conditions, MTT $(5 \mathrm{mg} / \mathrm{ml})$ was added to each well. The cells were cultured for a further $4 \mathrm{~h}$ before $100 \mu \mathrm{l}$ of dimethyl sulfoxide (Sigma-Aldrich; Merck KGaA) was added per well. Finally, absorbance was measured at $490 \mathrm{~nm}$ using an automated micro-plate reader (BioTek Instruments, Inc.).

Quantitative analysis of apoptosis. Cell apoptosis was quantified using the FITC-Annexin V/PI detection kit (Beijing Biosea Biotechnology Co. Ltd.) according to manufacturer's protocols. Briefly, cells were treated with lidocaine $(0.5,1,5,10 \mathrm{mM})$ for $48 \mathrm{~h}$ under hypoxic conditions. A total of $1 \times 10^{5}$ cells were collected from each sample and resuspended in $200 \mu \mathrm{l}$ of binding buffer containing $10 \mu \mathrm{l}$ of FITC-Annexin $\mathrm{V}$. The samples were then incubated at room temperature for $30 \mathrm{~min}$, and $300 \mu \mathrm{l}$ of PBS and $5 \mu \mathrm{l}$ of propidium idodide (PI) were added. The samples were immediately analyzed using a flow cytometer (Beckman Coulter, Inc.). FlowJo software (version 7.2.4; FlowJo LLC) was used to analyze the data and calculate levels of early and late stage apoptosis.

Western blot analysis. Total protein from H9c2 cells was isolated using RIPA lysis buffer (Beyotime Institute of Biotechnology). The protein concentration in whole cell extracts was quantified using a BCATM Protein Assay kit (Pierce, Thermo Fisher Scientific Inc.). Protein $(0.1 \mathrm{mg})$ from each sample was separated by $12 \%$ sodium dodecyl sulfate polyacrylamide gel electrophoresis and then transferred onto a nitrocellulose membrane. The membrane was blocked with $5 \%$ skim milk for $1 \mathrm{~h}$ at room temperature and then probed with primary antibodies: Bcl-2 (cat no. ab196495; 1:1,000; Abcam), Bax (cat no. 14796; 1:1,000; Cell Signaling Technology, Inc.), caspase-3 (cat no. 14220; 1:1,000; Cell Signaling Technology, Inc.), NF-кB p65 (cat no. 8242; 1:1,000; Cell Signaling Technology, Inc.), phosphorylated (p)-p65 (cat no. 3033; 1:1,000; Cell Signaling Technology, Inc.), ERK1/2 (cat no. 4695; 1:1,000; Cell Signaling Technology, Inc.), p-ERK1/2 (cat no. 4376; 1:1,000; Cell Signaling Technology, Inc.) and $\beta$-actin (cat no. 4970; 1:1,000; Cell Signaling Technology, Inc.), at $4^{\circ} \mathrm{C}$ overnight. The membranes were then incubated for $1 \mathrm{~h}$ at room temperature with the horseradish peroxidase-conjugated secondary antibody (cat no. 7074; 1:2,000; Cell Signaling Technology, Inc.). Positive bands from each group of samples were visualized using enhanced chemiluminescent reagent (ECL Advance Western Blotting Detection Kit; GE Healthcare Life Sciences) (27). The intensity of each band was quantified using Image $\mathrm{Lab}^{\mathrm{TM}}$ Software (version 5.2.1; Bio-Rad Laboratories Inc.).

Reverse transcription quantitative PCR (RT-qPCR). Total RNA was collected from cells using TRIzol ${ }^{\circledR}$ reagent (Thermo Fisher Scientific, Inc.) according to the manufacturer's instructions. cDNA was generated using a Transcriptor First Strand cDNA Synthesis kit (Roche Diagnostics) according to the manufacturer's protocol. The temperature protocol for the reverse transcription reaction consisted of primer annealing 

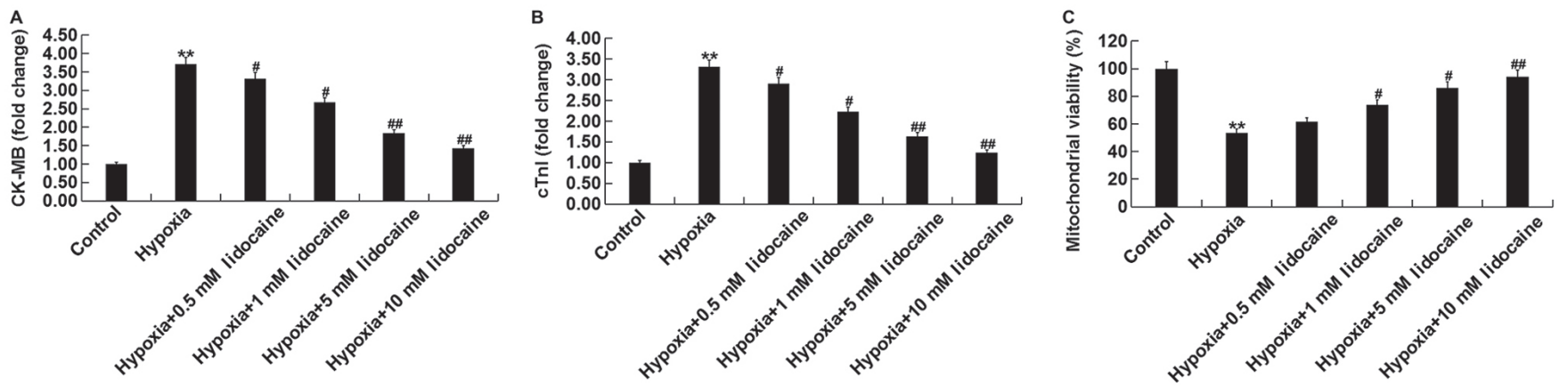

Figure 1. Effect of lidocaine treatment on H9c2 cell damage induced by hypoxia. The release of (A) CK-MB and (B) cTnI and (C) the mitochondrial survival rate were measured to determine the therapeutic effect of lidocaine on H9c2 cells under hypoxic conditions. The experimental data are presented as the mean \pm SD of fold change compared to control and the data are from three independent experiments. ${ }^{* *} \mathrm{P}<0.01$ vs. Control; ${ }^{\#} \mathrm{P}<0.05$ and ${ }^{\# \#} \mathrm{P}<0.01 \mathrm{vs}$. Hypoxia. cTnI, cardiac troponin I; CK-MB, creatine kinase-muscle/brain.

at $25^{\circ} \mathrm{C}$ for $5 \mathrm{~min}$, cDNA synthesis at $42^{\circ} \mathrm{C}$ for $60 \mathrm{~min}$ and termination at $80^{\circ} \mathrm{C}$ for $2 \mathrm{~min}$. FastStart Universal SYBR Green Master (Roche Diagnostics) was used to analyze cDNA levels. The thermocycling conditions were conducted as follows: Initial denaturation $95^{\circ} \mathrm{C}$ for $5 \mathrm{~min}$, followed by 40 cycles of denaturation at $95^{\circ} \mathrm{C}$ for $15 \mathrm{sec}$ and annealing/elongation at $60^{\circ} \mathrm{C}$ for $30 \mathrm{sec}$. The primer sequences used for qPCR were as follows: GAPDH forward, 5'-CTTTGGTATCGTGGAAGG ACTC-3' and reverse, 5'-GTAGAGGCAGGGATGATGTTC T-3'; IL-1 $\beta$ forward, 5'-TGTGAAATGCCACCTTTTGA-3' and reverse, 5'-TGAGTGATACTGCCTGCCTG-3'; TNF- $\alpha$ forward, 5'-GAACTGGCAGAAGAGGCACT-3' and reverse, 5'-GGTCTGGGCCATAGAACTGA-3' and IL-6 forward, 5'-CCGGAGAGGAGACTTCACAG-3' and reverse, 5'-CAG AATTGCCATTGCACA-3'. The target gene expression level was normalized to GAPDH. The $2^{-\Delta \triangle C q}$ method (28) was used to determine relative gene expression.

ELISA for inflammatory cytokines. Cells were treated with lidocaine $(0.5,1,5,10 \mathrm{mM})$ for $48 \mathrm{~h}$ under hypoxic conditions and the supernatants collected by centrifugation $(500 \mathrm{x} \mathrm{g}$; $5 \mathrm{~min} ; 4^{\circ} \mathrm{C}$ ) for the determination of levels of the inflammatory cytokines TNF- $\alpha$ (Rat TNF- $\alpha$ ELISA kit; cat. no. PT516), interleukin (IL)-6 (Rat IL-6 ELISA kit; cat. no. PI328) and IL-1 $\beta$ (Rat IL-1 $\beta$ ELISA kit; cat. no. PI303). All kits were obtained from Beyotime Institute of Biotechnology. ELISAs were performed according to the manufacturer's protocols and repeated three times.

Statistical analysis. The experimental results were expressed as the mean \pm SD from three independent experiments. Experimental data were analyzed using SPSS 16.0 software (SPSS, Inc.). Statistical significance was evaluated by one-way analysis of variance followed by Tukey's test. $\mathrm{P}<0.05$ was considered to indicate a statistically significant difference.

\section{Results}

Effect of lidocaine on hypoxia-induced cell damage. Rat cardiac myoblast cell line H9c2 was used in this study and they were used in the present study as a model for cardiac myocytes. The release of two biomarkers of cardiomyoblast

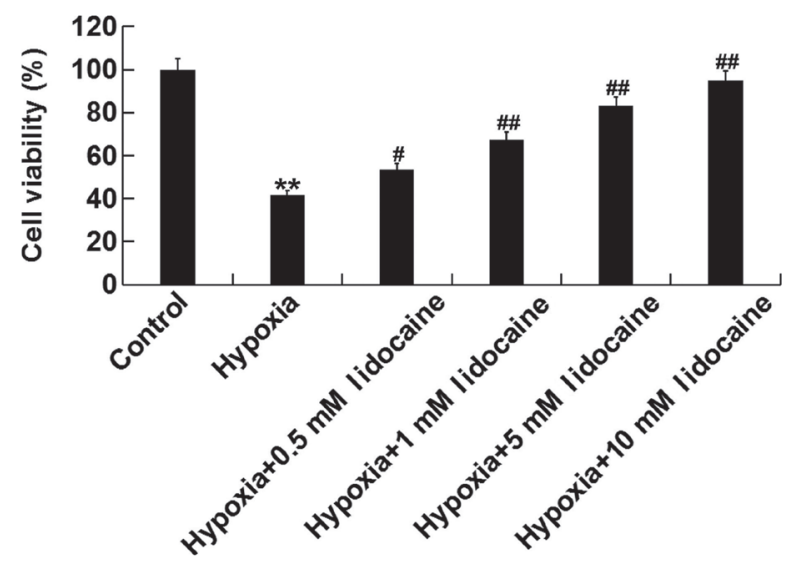

Figure 2. Effect of lidocaine on the viability of H9c2 cells under hypoxic conditions. H9c2 cell viability was examined by MTT assay. The experimental data are presented as the mean \pm SD and are from three independent experiments. ${ }^{* *} \mathrm{P}<0.01$ vs. Control; ${ }^{\#} \mathrm{P}<0.05$ and ${ }^{\# \#} \mathrm{P}<0.01$ vs. Hypoxia.

injury, CK-MB and cTnI, was measured to assess the effect of lidocaine on hypoxia-induced cell injury. Fig. 1A and B shows that the expression of both biomarkers, CK-MB and cTnI, were significantly increased relative to the control group due to hypoxia. Lidocaine significantly reduced the hypoxia-induced expression levels of CK-MB and $\mathrm{cTnI}$ in a dose-dependent manner. In addition, the results showed that hypoxia treatment of $\mathrm{H} 9 \mathrm{c} 2$ cells significantly reduced mitochondrial viability, and lidocaine treatment significantly increased mitochondrial viability under hypoxic conditions in a dose-dependent manner relative to the control group (Fig. 1C).

Effect of lidocaine on cell viability of hypoxic cardiomyoblasts. MTT assay was used to determine the effect of lidocaine on H9c2 cell viability under hypoxia. As shown in Fig. 2, H9c2 cell viability under hypoxia was significantly reduced relative to the control group, but lidocaine could significantly improve $\mathrm{H} 9 \mathrm{c} 2$ cell viability under hypoxia in a dose-dependent manner.

Effect of lidocaine on hypoxia-induced apoptosis of cardiomyoblasts. A FITC-Annexin V/PI detection kit was used to study the effects of lidocaine on hypoxia-induced apoptosis. As shown in Fig. 3A and B, compared with the control group, 
A

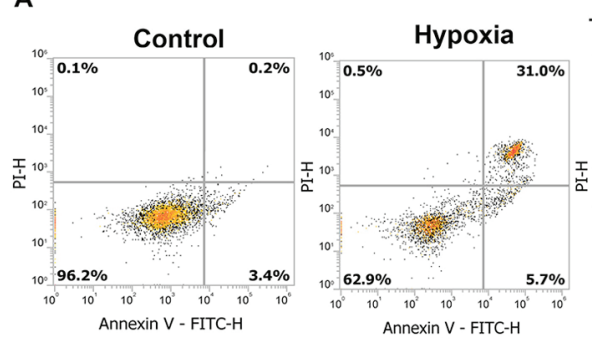

B

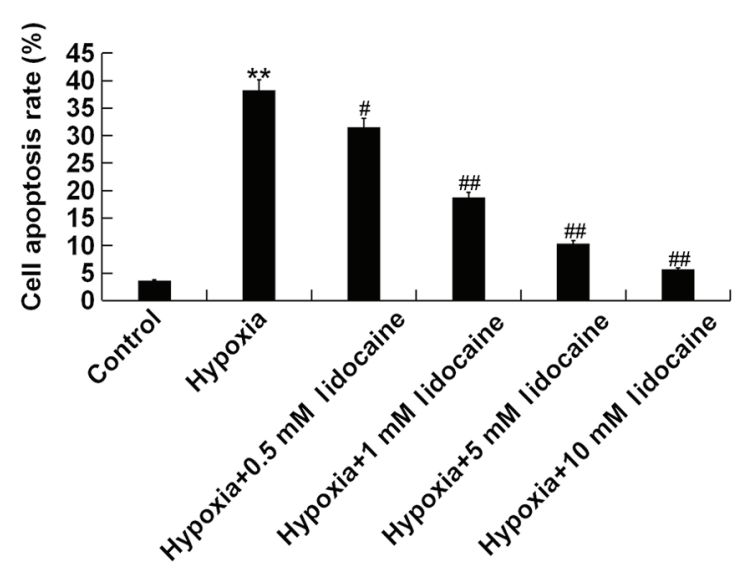

Hypoxia

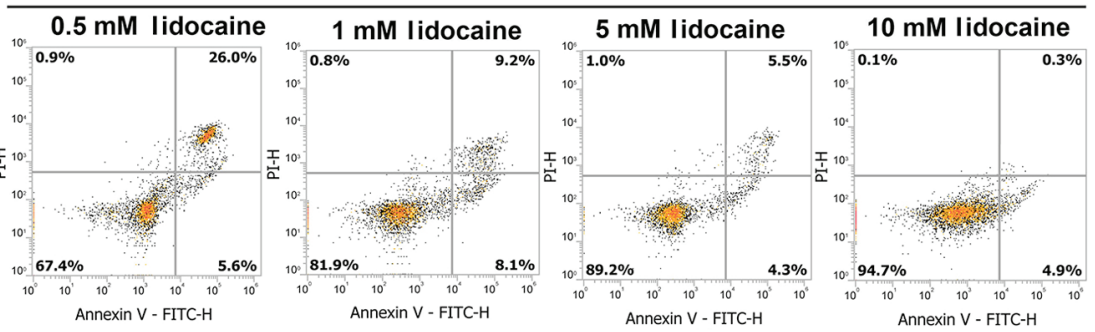

C

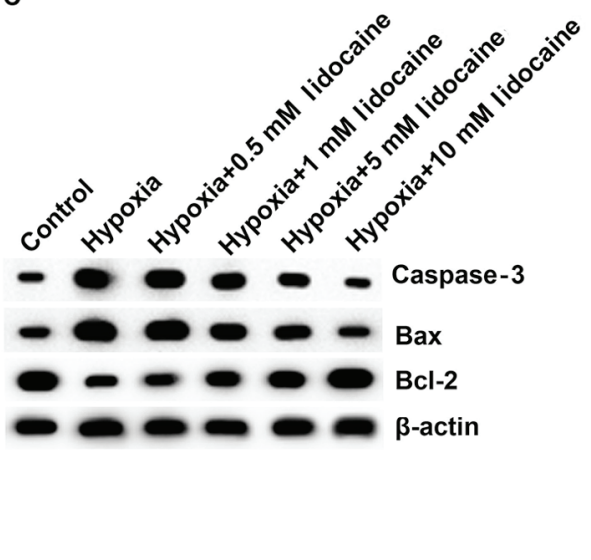

Figure 3. Effect of lidocaine on hypoxia-induced apoptosis of H9c2 cells. Cell apoptosis was measured using a FITC-Annexin V/PI detection kit. (A) Representative images of flow cytometry data and (B) apoptosis rates. (C) Representative images of western blotting analysis of Bax, Bcl-2 and caspase-3. ${ }^{* *} \mathrm{P}<0.01$ vs. Control; ${ }^{\#} \mathrm{P}<0.05$ and ${ }^{\# \#} \mathrm{P}<0.01$ vs. Hypoxia.

hypoxia significantly induced $\mathrm{H} 9 \mathrm{c} 2$ cell apoptosis, and lidocaine significantly decreased hypoxia-induced H9c2 cell apoptosis in a dose-dependent manner. To further determine the protective effect of lidocaine against hypoxia-induced H9c2 cell apoptosis, the expression levels of apoptosis-related proteins were determined experimentally. Western blotting showed that hypoxia-induction markedly increased Bax expression and decreased Bcl-2 expression relative to the control group, but lidocaine dose-dependently increased Bcl-2 and decreased Bax expression in the hypoxic cells. Western blotting was also used to detect the protein level of caspase-3 in $\mathrm{H} 9 \mathrm{c} 2$ cells. Levels of caspase-3 were markedly increased in hypoxic cells, but were reduced in these cells after lidocaine treatment in a dose-dependent manner (Fig. 3C). In summary, the results showed that lidocaine inhibited hypoxia-induced cardiomyoblast apoptosis, indicating that the drug had anti-apoptotic effects.

Lidocaine treatment inhibits the hypoxia-induced inflammatory response in cardiomyoblasts. The therapeutic effect of lidocaine on hypoxic cardiac myocytes was determined by measuring the levels of inflammatory cytokines IL-1 $\beta$, TNF- $\alpha$ and IL- 6 . The results of ELISA assay showed that the release of inflammatory cytokines increased significantly in $\mathrm{H} 9 \mathrm{c} 2$ cells under hypoxic conditions when compared with control. Lidocaine treatment significantly decreased the level of inflammatory cytokines released by hypoxic H9c 2 cells in a dose-dependent manner (Fig. 4A-C). Similar results were obtained from the RT-qPCR analysis of cytokine expression at the mRNA level (Fig. 4D-F). Together, these findings indicated that treatment with lidocaine inhibited the hypoxia-induced inflammatory response in cardiomyoblasts.
Effect of lidocaine on the MAPK/ERK/NF- $\kappa B$ signaling pathway in hypoxic cardiomyoblasts. The MAPK/ERK/NF- $\mathrm{B}$ signaling pathway was investigated in order to demonstrate the potential protective mechanism of lidocaine against hypoxia-induced cardiomyoblast injury. Western blot analysis showed that hypoxia inhibited MAPK/ERK/NF- $\mathrm{B}$ signaling in $\mathrm{H} 9 \mathrm{c} 2$ cells, as the cellular p-ERK1/2/ERK1/2 ratio was downregulated, whilst the p-p65/p65 ratio was upregulated compared with the control. Hypoxia-induced changes in expression of these phosphorylated proteins were alleviated by lidocaine treatment (Fig. 5).

\section{Discussion}

MI is pathologically defined as myocardial cell death caused by prolonged ischemia (29). The two most prominent features that can enhance each other during MI-induced cardiac injury are the physiological defects of the ischemic tissue and the sustained inflammatory response, which ultimately lead to heart failure. One of the major complications of MI treatment is hypoxia-induced cardiomyocyte death (30). Previous studies have shown that protection of cardiomyocytes from hypoxia-induced injury could lead to a potential treatment for MI $(31,32)$. The findings of the present study are consistent with previous studies $(31,32)$. After 48 h of hypoxia H9c2 cell viability was significantly impaired and cell apoptosis was induced, indicating that hypoxia does indeed cause cell damage in vitro.

cTnI and CK-MB are two well-known bio-markers of myocardial cell damage $(6,33)$. The present study found that after treatment with lidocaine, the levels of cTnI and 

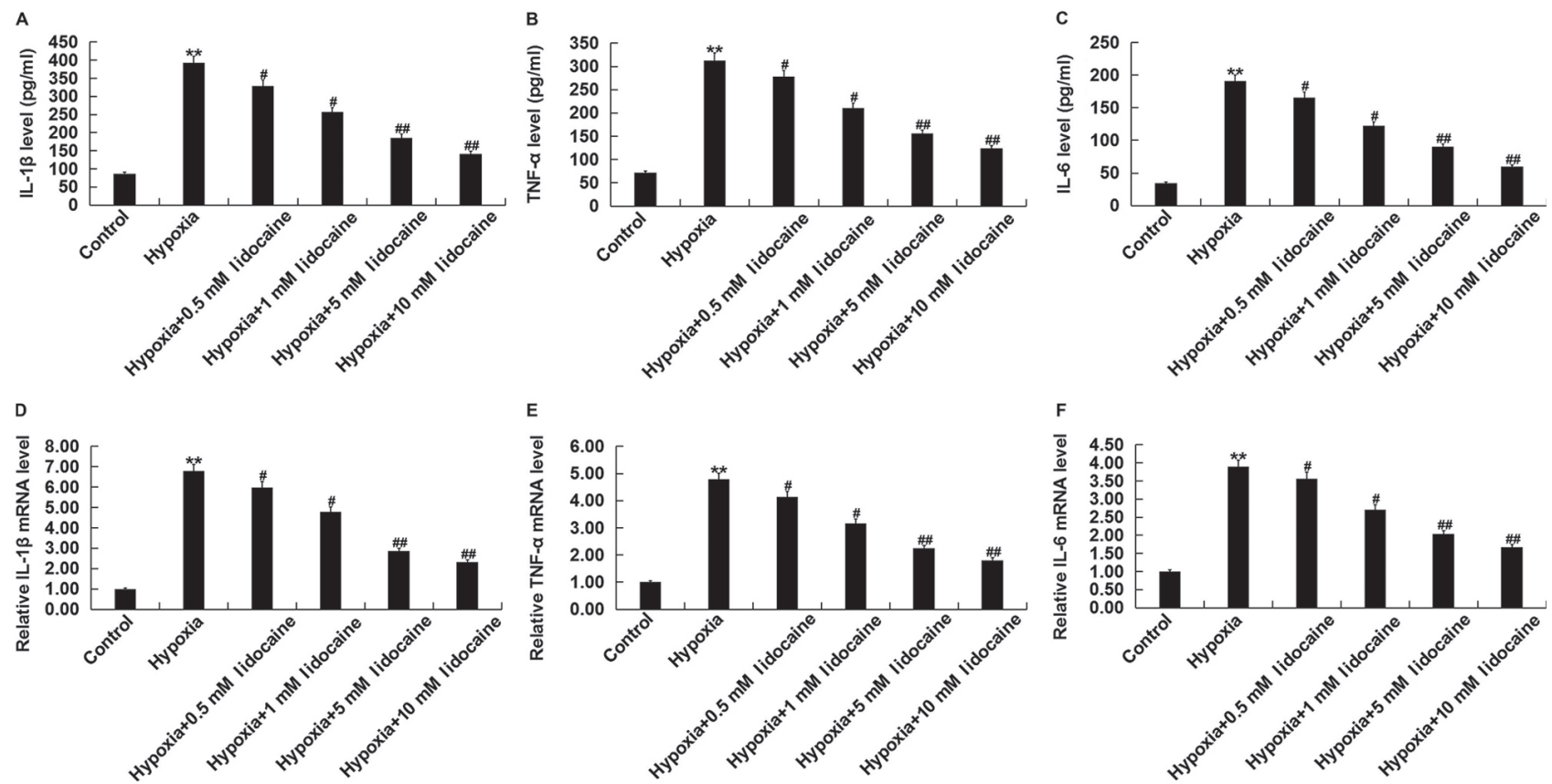

Figure 4. Effect of lidocaine on the hypoxia-induced inflammatory response of H9c2 cells. The concentrations of (A) IL-1 $\beta$, (B) TNF- $\alpha$ and (C) IL-6 were measured using ELISA kits. The mRNA levels of (D) IL-1 $\beta$, (E) TNF- $\alpha$ and (F) IL-6 were measured by reverse transcription-quantitative PCR. Data are presented as the mean $\pm \mathrm{SD} .{ }^{* *} \mathrm{P}<0.01$ vs. Control; ${ }^{\# P}<0.05$ and ${ }^{\# \#} \mathrm{P}<0.01$ vs. Hypoxia. IL, interleukin; mRNA, microRNA; TNF- $\alpha$, tumor necrosis factor- $\alpha$.
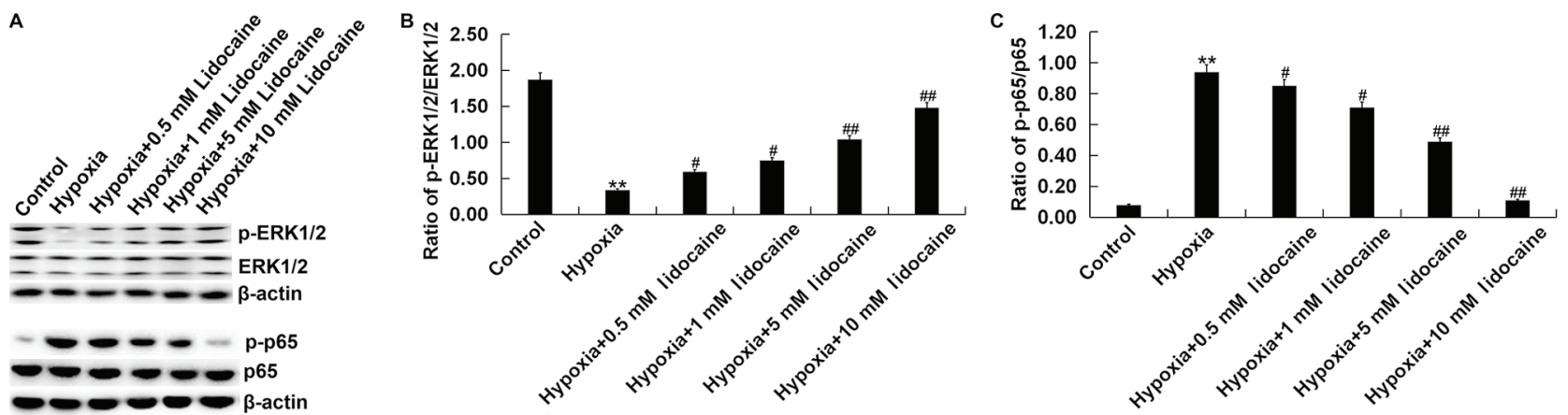

Figure 5. Effect of lidocaine on the MAPK/ERK/NF- $\mathrm{B}$ signaling pathway in H9c2 cells under hypoxic conditions. (A) Protein levels of ERK1/2,p-ERK1/2,

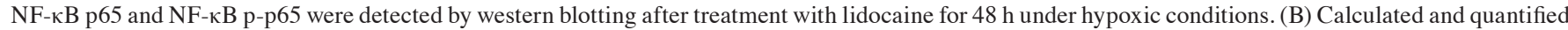
presented the ratios of p-ERK1/2/ERK1/2 and (C) p-p65/p65. Data are presented as the mean \pm SD. ${ }^{* *} \mathrm{P}<0.01$ vs. Control; ${ }^{\# P}<0.05$ and ${ }^{\# \#} \mathrm{P}<0.01$ vs. Hypoxia. MAPK, mitogen activated protein kinase; p, phosphorylated.

CK-MB in hypoxia-treated cells were significantly reduced when compared with controls, indicating that treatment with lidocaine reduced myocardial cell damage. In addition, it was found in the present study that lidocaine promoted cell viability and inhibited apoptosis in a dose-dependent manner to protect $\mathrm{H} 9 \mathrm{c} 2$ cells from damage.

Lidocaine is used in the treatment of acute myocardial infarction and other heart diseases complicated by rapid ventricular arrhythmia (34). To evaluate the molecular mechanisms underlying the potential benefits of lidocaine in MI, hypoxic H9c2 cells were used as a cellular model of MI. The findings of the present study indicated that a hypoxic environment significantly inhibited myocardial cell viability and induced apoptosis, which were reversed by lidocaine treatment. To further confirm the anti-apoptotic activity of lidocaine on hypoxia induced H9c2 cells, proteins associated with apoptosis, including Caspase 3,
Bax and Bcl-2, were detected in the present study. The Bcl-2 family consists of a group of proteins which regulate apoptosis (35). In particular, increases in the $\mathrm{Bax} / \mathrm{Bcl}-2$ expression ratio has been reported to activate caspase-3 protease activity in cardiomyocytes, leading to programmed cell death (36). Consistent with the findings of Zhang et al (37) and Li et al (38), the present study demonstrated that hypoxia-induction markedly increased Bax and Caspase- 3 expression whilst decreasing Bcl-2 expression compared with the control group. However, lidocaine dose-dependently increased Bcl-2 and decreased Bax and Caspase-3 expression in hypoxic H9c2 cells.

Accumulating evidence demonstrates that the inflammatory response serves critical roles in MI pathogenesis $(5,39)$. Increased expression of a multiple endogenous inflammatory cytokines can lead to myocardial dysfunction. The findings of the present study were consistent with a previous study (9), 
which indicated that hypoxia promotes an inflammatory response in cardiomyocytes due to increased secretion of the cytokines IL-6, IL- $1 \beta$ and TNF- $\alpha$. The results of the present study suggested that lidocaine treatment might effectively reduce hypoxia-induced inflammation.

Myocardial ischemia and hypoxia activate several protein kinase pathways (40). Increased activation of the p38-MAPK, ERK1/2 and JNK pathways occurs during ischemia-reperfusion (41). Research has shown that during myocardial damage, pro-inflammatory cytokine levels are elevated in a manner that is dependent on NF- $\mathrm{kB}$ activation (42). It has been shown that, in treatment of the ischemic myocardium, activation of the MAPK/ERK/NF- $\mathrm{BB}$ pathway is essential in preventing cardiomyocyte death, which can be achieved by ischemic post-conditioning or administration of certain pharmacological agents $(6,41,43)$. The results of the present study suggested that lidocaine activated the MAPK/ERK/NF- $\mathrm{KB}$ signaling pathway through a significant upregulation in ERK1/2 phosphorylation and a downregulation of p-p65 levels, and may protect cells against hypoxia-induced damage.

In summary, the present study highlighted the protective effect of lidocaine against hypoxia-induced damage to cardiomyoblasts and suggested a role for lidocaine treatment in MI. However, this study was only preliminary and further in vitro and in vivo study with a greater range of lidocaine concentrations is necessary to confirm these results.

\section{Acknowledgements}

The authors would like to thank Dr Gao Bo, director of the Department of Cardiology, Tianjin Hospital (Tianjin, China) for the help and guidance he provided.

\section{Funding}

No funding was received.

\section{Availability of data and materials}

All datasets used and/or generated during the present study are available from the corresponding author on reasonable request.

\section{Authors' contributions}

HBJ contributed to study design, data collection, statistical analysis, data interpretation and manuscript preparation. JY contributed to data collection and statistical analysis.

\section{Ethical approval and consent to participate}

Not applicable.

\section{Patient consent for publication}

Not applicable.

\section{Competing interests}

The authors declare that they have no competing interests.

\section{References}

1. Moran AE, Forouzanfar MH, Roth GA, Mensah GA, Ezzati M, Flaxman A, Murray CJ and Naghavi M: The global burden of ischemic heart disease in 1990 and 2010: The Global Burden of disease 2010 study. Circulation 129: 1493-1501, 2014.

2. Boateng $\mathrm{S}$ and Sanborn T: Acute myocardial infarction. Dis Mon 59: 83-96, 2013.

3. Lu L, Liu M, Sun R, Zheng Y and Zhang P: Myocardial Infarction: Symptoms and treatments. Cell Biochem Biophys 72: 865-867, 2015

4. Johansson S, Rosengren A, Young K and Jennings E: Mortality and morbidity trends after the first year in survivors of acute myocardial infarction: A systematic review. BMC Cardiovasc Disord 17: 53, 2017.

5. Chen-Scarabelli C, Saravolatz L Jr, Murad Y, Shieh WS, Qureshi W, Di Rezze J, Abrencillo R, Gardin T, Gidwani UK, Saravolatz L, et al: A critical review of the use of carvedilol in ischemic heart disease. Am J Cardiovasc Drugs 12: 391-401, 2012.

6. Gong L, Chang H, Zhang J, Guo G, Shi J and Xu H: Astragaloside IV protects rat cardiomyocytes from hypoxia-induced injury by down-regulation of miR-23a and miR-92a. Cell Physiol Biochem 49: 2240-2253, 2018.

7. Yan L, Yang H, Li Y, Duan H, Wu J, Qian P, Li B and Wang S: Regulator of calcineurin 1-1L protects cardiomyocytes against hypoxia-induced apoptosis via mitophagy. J Cardiovasc Pharmacol 64: 310-317, 2014.

8. Task Force on the management of ST-segment elevation acute myocardial infarction of the European Society of Cardiology (ESC); Steg PG, James SK, Atar D, Badano LP, Blömstrom-Lundqvist C, Borger MA, Di Mario C, Dickstein K, Ducrocq G, et al: ESC Guidelines for the management of acute myocardial infarction in patients presenting with ST-segment elevation. Eur Heart J 33: 2569-2619, 2012.

9. Yuan M, Zhang L, You F, Zhou J, Ma Y, Yang F and Tao L: MiR-145-5p regulates hypoxia-induced inflammatory response and apoptosis in cardiomyocytes by targeting CD40. Mol Cell Biochem 431: 123-131, 2017.

10. Marchant DJ, Boyd JH, Lin DC, Granville DJ, Garmaroudi FS and McManus BM: Infammation in myocardial diseases. Circ Res 112: 126-144, 2012.

11. Sun M, Dawood F, Wen WH, Chen M, Dixon I, Kirshenbaum LA and Liu PP: Excessive tumor necrosis factor activation after infarction contributes to susceptibility of myocardial rupture and left ventricular dysfunction. Circulation 110: 3221-3228, 2004.

12. Tare M, Bensley JG, Moss TJ, Lingwood BE, Kim MY, Barton SK, Kluckow M, Gill AW, De Matteo R, Harding R, et al: Exposure to intrauterine inflammation leads to impaired function and altered structure in the preterm heart of fetal sheep. Clin Sci (Lond) 127: 559-569, 2014.

13. Mandel I, Podoxenov Y, Suhodolo I, Podoxenov A, Svirko Y, Kamenschikov N, Mikheev S, Sementsov A, Dzuman A and Maslov L: Hypoxic and hyperoxic preconditioning in myocardial protection against ischemia-reperfusion injury: Experimental study. J Cardiothor Vasc Anes 30 (Suppl 1): S6-S7, 2016.

14. Carson IW, Lyons SM and Shanks RG: Anti-arrhythmic drugs. Br J Anaest 51: 659-670, 1979.

15. Khan SU, Winnicka L, Saleem MA, Rahman H and Rehman N: Amiodarone, lidocaine, magnesium or placebo in shock refractory ventricular arrhythmia: A Bayesian network meta-analysis. Heart Lung 46: 417-424, 2017.

16. Caracas HC, Maciel JV, Martins PM, de Souza MM and Maia LC: The use of lidocaine as an anti-inflammatory substance: A systematic review. J Dent 37: 93-97, 2009.

17. Fukuda S, Nojima J, Motoki Y, Yamaguti K, Nakatomi Y, Okawa N, Fujiwara K, Watanabe Y and Kuratsune H: A potential biomarker for fatigue: Oxidative stress and anti-oxidative activity. Biol Psych 118: 88-93, 2016.

18. Li H, Li C, Zhang H, Zhang L, Cheng R, Li M, Guo Y, Zhang Z, Lu Z, Zhuang Y, et al: Effects of lidocaine on regulatory Tcells in atopic dermatitis. J Allergy Clin Immun 137: 613-617.e5, 2016.

19. Bundscherer AC, Malsy M, Bitzinger DI, Wiese CH, Gruber MA and Graf BM: Effects of Lidocaine on HT-29 and SW480 colon cancer cells in vitro. Anticancer Res 37: 1941-1945, 2017.

20. Ye L, Zhang Y, Chen YJ and Liu Q: Anti-tumor effects of lidocaine on human gastric cancer cells in vitro. Bratisl Lek Listy 120: 212-217, 2019. 
21. Župčić M, Graf Župčić S, Duzel V, Šimurina T, Šakić L, Fudurić J, Peršec J, Milošević M, Stanec Z, Korušić A and Barišin S: A combination of levobupivacaine and lidocaine for paravertebral block in breast cancer patients undergoing quadrantectomy causes greater hemodynamic oscillations than levobupivacaine alone. Croat Med J 58: 270-280, 2017.

22. Maurice JM, Gan Y, Hibner M and Huang Y: Bupivacaine causes cytotoxicity via extracellular signal-regulated kinase (ERK) and Akt pathways in mouse myoblast C2C12 Cells. J Minim Invas Gyn 16 (Suppl): S11-S12, 2009.

23. Müller-Edenborn B, Kania G, Osto E, Jakob P, Krasniqi N, Beck-Schimmer B, Blyszczuk P and Eriksson U: Lidocaine enhances contractile function of ischemic myocardial regions in mouse model of sustained myocardial ischemia. PLoS One 11: e0154699, 2016

24. Kaczmarek DJ, Herzog C, Larmann J, Gillmann HJ, Hildebrand R, Schmitz M, Westermann A, Harendza T, Werdehausen R, Osthaus AW, et al: Lidocaine protects from myocardial damage due to ischemia and reperfusion in mice by its antiapoptotic effects. Anesthesiology 110: 1041-1049, 2009.

25. Okamoto A, Sumi C, Tanaka H, Kusunoki M, Iwai T, Nishi K, Matsuo Y, Harada H, Takenaga $\mathrm{K}$, Bono $\mathrm{H}$ and Hirota $\mathrm{K}$ : HIF-1-mediated suppression of mitochondria electron transport chain function confers resistance to lidocaine-induced cell death Sci Rep 7: 3816, 2017

26. Chang YC, Hsu YC, Liu CL, Huang SY, Hu MC and Cheng SP Local anesthetics induce apoptosis in human thyroid cancer cells through the mitogen-activated protein kinase pathway. PLoS One 9: e89563, 2014.

27. Fantetti KN, Gray EL, Ganesan P, Kulkarni A and O'Donnell LA: Interferon gamma protects neonatal neural stem/progenitor cells during measles virus infection of the brain. J Neuroinflamm 13 $107,2016$.

28. Livak KJ and Schmittgen TD: Analysis of relative gene expression data using real-time quantitative PCR and the 2(-Delta Delta C(T)) method. Methods 25: 402-408, 2001.

29. Choi CW, Hwang JH, Chang YS, Shin SM, Park WS and Lee M: Effects of alpha-phenyl-N-tert-butyl nitrone (PBN)on brain cell membrane function and energy metabolism during transient global cerebral hypoxia-ischemia and reoxygenation-reperfusion in newborn piglets. J Korean Med Sci 19: 413-418, 2004.

30. Vorobieva VV and Shabanov PD: Vibration model for hypoxic type of cell metabolism evaluated on rabbit cardiomyocytes. Bull Exp Biol Med 147: 768-771, 2009.

31. Han F, Chen Q, Su J, Zheng A, Chen K, Sun S, Wu H, Jiang L, $\mathrm{Xu}$ X, Yang M, et al: MicroRNA-124 regulates cardiomyocyte apoptosis and myocardial infarction through targeting Dhcr24. J Mol Cell Cardiol 132: 178-188, 2019.
32. Zhang J, Qiu W, Ma J, Wang Y, Hu Z, Long K, Wang X, Jin L, Tang Q, Tang G, et al: miR-27a-5p attenuates hypoxia-induced rat cardiomyocyte injury by inhibiting Atg7. Int J Mol Sci 20: pii: E2418, 2019.

33. Deng F, Wang S, Zhang L, Xie X, Cai S, Li H, Xie GL, Miao HL, Yang C, Liu X and Xia Z: Propofol through upregulating caveolin-3 attenuates post-hypoxic mitochondrial damage and cell death in $\mathrm{H} 9 \mathrm{C} 2$ cardiomyocytes during hyperglycemia. Cell Physiol Biochem 44: 279-292, 2017.

34. Martí-Carvajal AJ, Simancas-Racines D, Anand V and Bangdiwala S: Prophylactic lidocaine for myocardial infarction. Cochrane Database Syst Rev: CD008553, 2015.

35. Daido S, Tamiya T, Ono Y, Terada K, Mizumatsu S and Ohmoto T: Expression of Bcl-2, Bcl-x and Bax proteins in astrocytomas in relation to patient survival. Biochem Biophys Res Commun 18: 123-129, 2001

36. Tamatani M, Ogawa S, Nuñez G and Tohyama M: Growth factors prevent changes in Bcl-2 and Bax expression and neuronal apoptosis induced by nitric oxide. Cell Death Differ 5: 911-919, 1998.

37. Zhang J, Xia Y, Xu Z and Deng X: Propofol suppressed Hypoxia/Reoxygenation-induced apoptosis in HBVSMC by regulation of the expression of Bcl-2, Bax, Caspase3, Kir6.1, and p-JNK. Oxid Med Cell Longev 2016: 1518738, 2016.

38. LiH, Lv B, Kong L, Xia J,Zhu M,Hu L, Zhen D, Wu Y, Jia X, Zhu S and Cui H: Noval mediates resistance of rat pheochromocytoma cells to hypoxia-induced apoptosis via the Bax/Bcl-2/caspase-3 pathway. Int J Mol Med 40: 1125-1133, 2017.

39. Frangogiannis NG: The inflammatory response in myocardial injury, repair, and remodelling. Nat Rev Cardiol 11: 255-265, 2014.

40. Ferdinandy P, Schulz R and Baxter GF: Interaction of cardiovascular risk factors with myocardial ischemia/reperfusion injury, preconditioning, and postconditioning. J Pharmacol Rev 59: 418-458, 2007.

41. Milano G, Morel S, Bonny C, Samaja M, von Segesser LK, Nicod P and Vassalli G: A Peptide inhibitor of c-Jun NH2-terminal kinase reduces myocardial ischemia-reperfusion injury and infarct size in vivo. Am J Physiol Heart Circ Physiol 292: H1828-H1835, 2007.

42. Wei H, Li H, Wan SP, Zeng QT, Cheng LX, Jiang LL and Peng YD: Cardioprotective effects of Malvidin against isoproterenol-induced myocardial infarction in rats: A mechanistic study. Med Sci Monit 23: 2007-2016, 2017.

43. Chen Y, Ba L, Huang W, Liu Y, Pan H, Mingyao E, Shi P, Wang Y, Li S, Qi H, et al: Role of carvacrol in cardioprotection against myocardial ischemia/reperfusion injury in rats through activation of MAPK/ERK and Akt/eNOS signaling pathways. Eur J Pharmacol 796: 90-100, 2017. 